\title{
STUDY ON SEDIMENT DISASTERS IN TENNOU, KURE CITY, HIROSHIMA PREFECTURE AND SEDIMENT AND FLOOD DAMAGE IN DOWNSTREAM AREA
}

\author{
Yuji HASEGAWA ${ }^{1}$, Kana NAKATANI ${ }^{2}$, Yoshinori ARAKI ${ }^{3}$, Masahiro KAIBORI ${ }^{4}$ \\ and Yoshifumi SATOFUKA 5
}

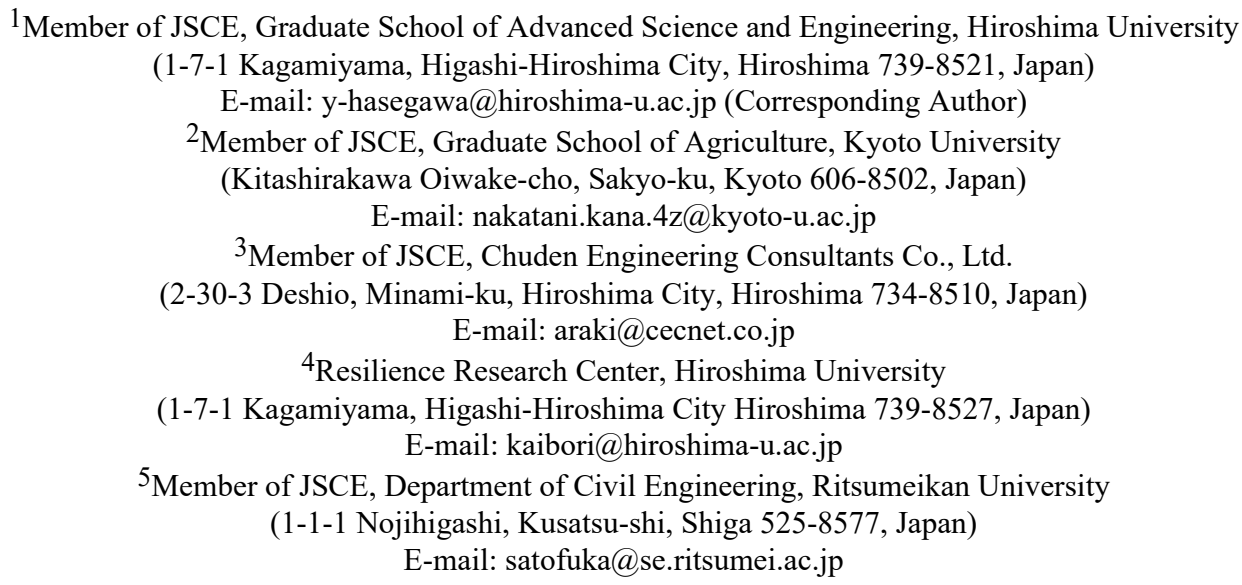

Due to heavy rains in July 2018, many sediment disasters occurred in western Japan. Not only were there direct damage caused by debris flows, such as destructed buildings, but some places several kilometers downstream from the landslides and debris flows also experienced flooding that lasted several hours and sediment deposition from the rivers. In this study, we focused on Tennou, Kure City in Hiroshima Prefecture, aimed to study the disaster situation in detail, and applied simulations. In Tennou, debris flows occurred and large boulders moved upstream. Sediment movement occurred but did not cause flooding outside the midstream river. Deposition and flooding occurred outside the downstream river. Downstream, deposition occurred at the upstream side of the box culvert but did not occur downstream; thus, it was assumed that blocking due to sediment occurred at the culvert. In the simulations, we considered the culvert blocking, and also considered sediment runoff continuing for many hours, which was different from shorttime debris flow. From the simulation results, the flooding and deposition outside the river first occurred at the blocked culvert point. However, as the runoff continued, the riverbed rising from deposition became larger in the upstream side. Flooding and deposition outside the river also occurred in the upstream area from the culvert.

Key Words : 2018 July heavy rains, sediment and flood damage, field survey, numerical simulation

\section{INTRODUCTION}

Typhoon Prapiroon, which passed from western Kyushu to the Sea of Japan on July 3, 2018, supplied large amounts of moisture to the rainy season front. This caused continuous rainfall throughout western Japan from July 5, which caused sediment disasters such as landslides and debris flows in many areas. The number of deaths and missing persons totaled
245 in 13 prefectures, and 120 (including 5 missing) in Hiroshima Prefecture. The highest number of victims in Hiroshima Prefecture was in Kure City. Hiroshima Prefecture had experienced a number of huge sediment disasters caused by heavy rains, such as the Kake Town (now Akiota Town) in 1988, the June 29th Hiroshima Sediment Disaster in 1999, and the August 20th Hiroshima Sediment Disaster in 2014, and the damage from sediment disasters has been in 
creasing $^{1), 2)}$.

On the sediment disasters caused by the heavy rain event of July 2018, there had been reports of sediment and flood damage caused by sediment flowing into residential areas several kilometers downstream from the collapse site in Tennou Kure City, Koyaura Saka-cho and Saka Saka-cho ${ }^{3)}$. The upstream of the basin consists of a valley plain and both sides of the river are surrounded by steep slopes. Therefore, when sediment deposition occurs, the riverbed only rises, but does not spread widely. If the longitudinal slope of the current river becomes steep and sediment runoff continues for a long time, there is a possibility that sediment will move downstream. The slope of a river usually becomes mild on the downstream side, and sediment deposition tends to occur in the downstream of the channel. Due to the river bed rise from deposition, the sediment and flood damage that cause flooding and deposit overflowing from the river seem to occur.

The disaster situations were different from debris flow in which sediment moved more to the downstream side from the sediment disaster-prone areas. In a designated high-risk area, building damage is generally assumed due to the direct impact of debris flow. Events are assumed to happen within a short time; i.e., from several minutes up to ten minutes with several meters of flow depth and deposition. However, the phenomena of this event were different. Sediments were gradually deposited on the river due to flood, and there was also flooding and deposition outside of the river, causing several meters of deposition in the surrounding roads and burying the lower floors of buildings. It is necessary to examine the factors and the process of the phenomenon because the influence of sediments and flood damage spread widely in the downstream area. In this study, we aimed to clarify the disaster situation by field survey and to understand the time series phenomenon of sediment and flood damage using numerical simulation, targeting the Tennou area where the damage to humans was the highest.

\section{FIELD INVESTIGATION RESULTS IN TENNOU, KURE CITY}

Figure 1 shows the rainfall data of the rain gauge station at Tennou, Kure City. The rain started from 9:00 on July 5 and continued until 9:00 on July 7. Then it stopped for a while, and continued raining for 15 hours from 21:00 on July 7. It went on for 82 hours from the beginning to the end of the event. Total rainfall was $459 \mathrm{~mm}$, with a maximum hourly rainfall of $55 \mathrm{~mm} / \mathrm{h}$ and a maximum 24 hour rainfall of $305 \mathrm{~mm}$. Calculating from the probability rainfall intensity equation for Hiroshima Prefecture, hourly rainfall corresponds to approx. 12 years return period and 24 hours. Rainfall corresponds to approx. 168 years return period. Compared to the past sediment disasters' rainfall data in Hiroshima Prefecture, the hourly rainfall is small, but the total rainfall is large, and the rainfall duration is long.

Figure 2 shows a longitudinal section of the main river Oya-Ohkawa and the field investigation results. In the River where sediment and flood damage occurred in the downstream of the basin, the flow characteristic was different in the upstream and midstream of the basin. Hereafter, we call the area as upstream, midstream, and downstream. The collapse site of the upstream was $14 \mathrm{~m}$ wide, $16 \mathrm{~m}$ long, and $1.0 \mathrm{~m}$ deep. The bed of the downstream was bare and covered with relatively fresh $1.5-2.0 \mathrm{~m}$ diameter boulders. There were many exposed rocks on the riverbed, and sediment and woody debris accumulated. We assumed that not only the collapse occurred, but also the afforestation on the riverbank was eroded and moved as woody debris. The existing sabo dam, shown in Fig.2, 0.5-2.0 $\mathrm{m}$ diameter of gravel and woody debris deposited in the upstream surface layer. Traces of sediment runoff was left upstream of the dam. Boulders and woody debris were accumulated in the series of ground sills down-stream, but no boulders or woody debris were found in the residential areas further downstream. Focusing on the longitudinal slope, the slope becomes milder from upstream

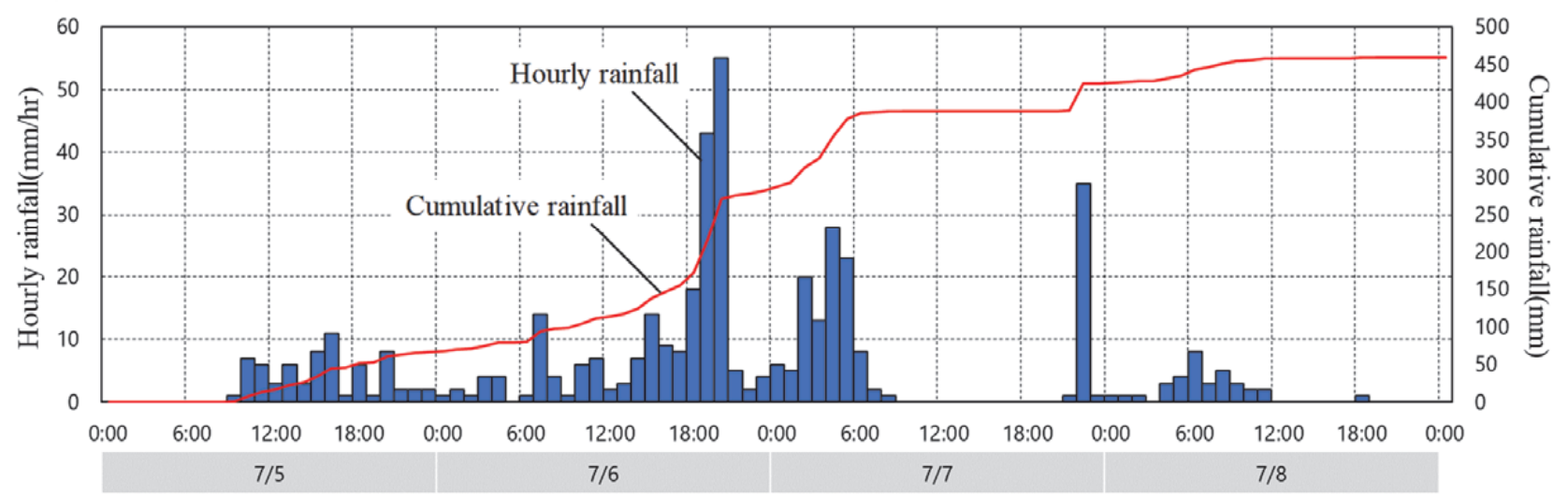

Fig.1 Diagram of rainfall at Tenno station, Hiroshima Prefecture. 

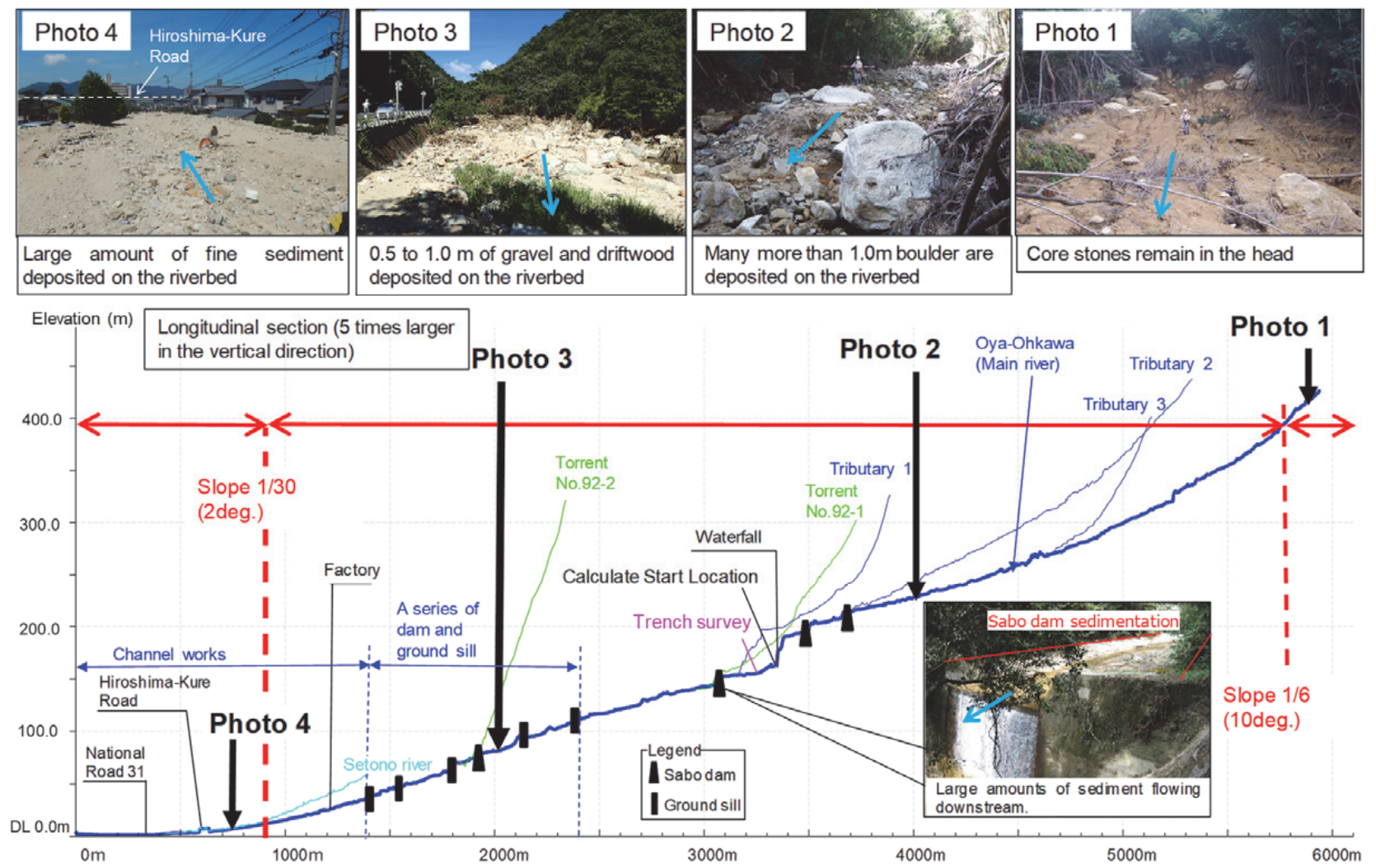

Fig.2 Longitudinal section of the main river Oya-Ohkawa and the field investigation results.

to downstream, so selective transport by grain size occurred in this section. Structures may have contributed to the trapping of large gravels and wood debris due to the sediment conditions in sabo dams and ground sills.

Figure 3 shows the results of the trench survey on sedimentation upstream of the sabo dam located in the middle stream of Oya-Ohkawa. We used a backhoe to take one sample of $2 \mathrm{~m}$ width, $5 \mathrm{~m}$ length, and $2 \mathrm{~m}$ depth, and conducted a grain size test in five layers from the surface layer to the lower layer in vertical direction. Figure 4 shows the results of grain size distribution. It was confirmed that each layer had different grain size and there were five layers of sediment deposited on the sabo dam. The bottom layer was an old sediment deposition containing deciduous leaves. Although the grain size of the front part and the subsequent flow may be different even in one debris flow and formed several layers, we considered that the upper layers except for the bottom old sediment was deposited by four sediment runoffs in this paper. We focused on the grain size distribution of each layer. The second and fourth layers showed the same grain size distribution and were smaller in size than the first and third layers. This was probably because sediment production occurred at each flood and formed deposit layer and also because the runoff scale was different.

Figure 5 shows the results of trace surveys of the sediment deposition area, inundation damage area,

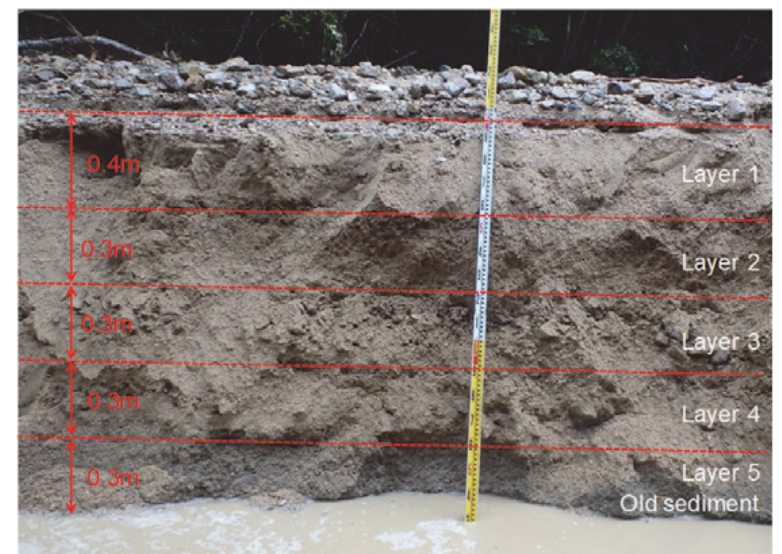

Fig.3 Results of the trench survey on sedimentation upstream of the sabo dam.

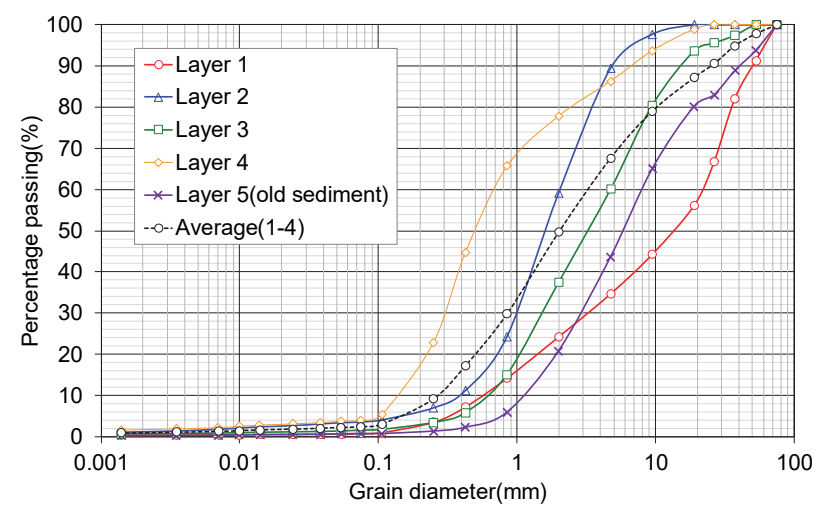

Fig.4 Trench survey results of grain size distribution.

and flooding area around the downstream residential 


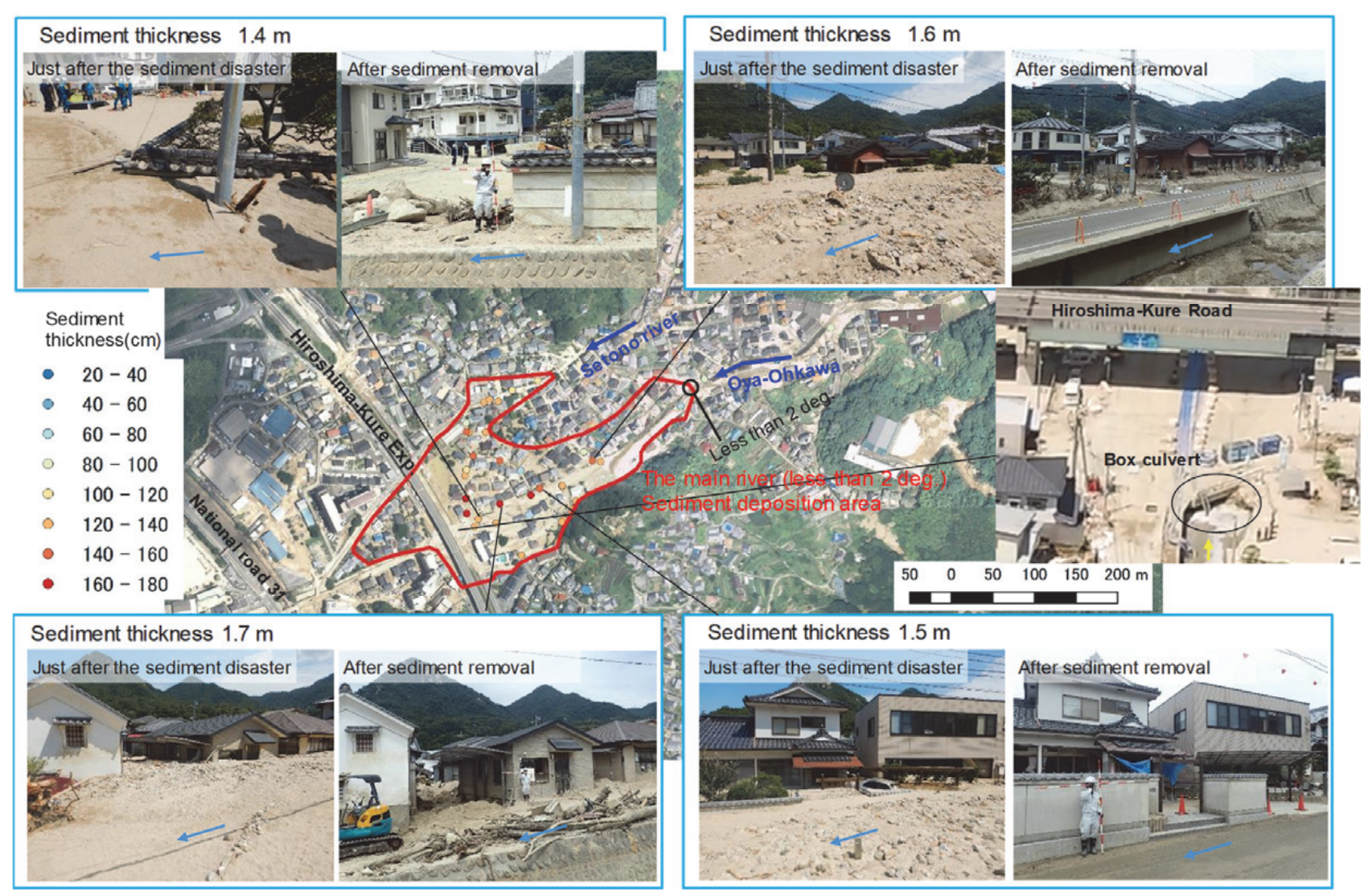

Fig.5 Trace survey results of the sediment deposition area, inundation damage area, and flooding area around the downstream residential area.

area. The sediment thickness and inundation depth were measured by comparing traces just after the sediment disaster and after sediment removal, and also by using aerial photographs. The widest area of sediment deposition was from the area with longitudinal slope, which was less than $2 \mathrm{deg}$. to the Hiroshima Kure Road. A box culvert with a longitudinal crosssection approx. $50 \mathrm{~m}$ existed in the river where the Hiroshima-Kure Road is located. It appeared to be blocked by sediment deposition during the heavy rain. As a result, flooding and sedimentation occurred upstream of the box culvert. The flooding spread much wider on the right bank side of the river than on the left bank side, and was partly influenced by the Setono River branch.

The sediment deposition occurred approx. $350 \mathrm{~m}$ in the longitudinal direction and maximum $230 \mathrm{~m}$ in the transverse direction upstream from the Hiroshima Kure Road. The maximum sediment height was $1.7 \mathrm{~m}$ and was remarkable around the river $120 \mathrm{~m}$ upstream from the box culvert. On each site shown in the photograph, sediment height was approx. $1.5 \mathrm{~m}$. According to the Hiroshima Prefecture report ${ }^{4)}$, the estimated time of sediment disasters' occurrence in Tennou was 19:00-21:00 on July 6 based on information from the police and fire departments. The evacuation order was canceled in the morning on July 9. After the release, it was confirmed that the river and houses were buried with sediment deposition for several meters. From the situations of houses shown on the upper right and lower left of Fig.5, it is estimated that the sediment deposition progressed over a long period of time, taking dozens of hours to deposit, without the destruction or significant damage usually seen in debris flows.

\section{DEBRIS FLOW SIMULATIONS}

In applying sediment runoff simulations in Tennou, Kure City, we used the geographic information

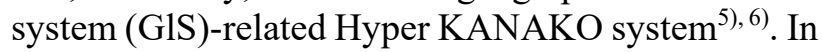
the Hyper KANAKO system, the applied sediment runoff simulation model is proposed by Takahashi ${ }^{7}$ including debris flow, sediment sheet flow, and bed load. The model considers the erosion/deposition due to equilibrium concentrations. It includes equations of momentum considering riverbed shearing stress, continuation, riverbed deformation, and erosion/deposition. The authors applied Hyper KANAKO for other sediment runoff cases that occurred and confirmed the validity of the flow behaviors and deposition distributions. In the simulations, we assumed that culverts located on Hiroshima Kure Road to be blocked and the flows to move down on the roads from the culverts. 


\section{(1) Landform data}

We applied the digital elevation model (DEM) data, the ground elevation in which the heights of the buildings and trees were excluded with a $1 \mathrm{~m}$ mesh resolution taken before the 2018 disaster with airborne LiDAR. In this study, we set a 1D simulation area and 2D simulation area. Usually, 1D area is set where the valley is deep and both sides are surrounded by steep slope. In the $1 \mathrm{D}$ area, it is suitable that the flow direction is controlled only for the longitudinal directions, and will not spread in transverse directions. However, the phenomenon that occurred in Tennou did not show typical debris flows characterized by large discharge, high sediment concentration within a short time. It is assumed that smaller discharge flow occurred after the debris flow. Riverbed erosion and lower concentration of sediment runoff continued for a long period, and caused sediment runoff to the downstream side. Therefore, erosion occurred due to the subsequent flow from the deposition in the upstream region of sabo dam. In this study, we aimed to consider the erosion of the deposition from debris flow, cross-sectional river variation from erosion/deposition, and river shape. Thus, we set a wide $2 \mathrm{D}$ area from the steep valley area to the downstream side.

As shown in the red square in Fig.6 designated as 2D area, we set a 1D area upstream of the inflow point measuring $50 \mathrm{~m}$ long. The $1 \mathrm{D}$ area was set as the supplying section of the water and sediment. In the upstream area, it was assumed that four sediment runoffs occurred from the survey of the deposition upstream of the sabo dam. Each event might happen in different discharge, moved sediment and other conditions, but in this study, we set all four events on the same scale and conditions. Not to affect the former event by the latter one, we set an interval time after each runoff with the same time period of the runoff continuance time. From the simulation start point, we supplied water and sediment as described in the latter paragraph (2). In the disaster situation, the moved sediment volume was larger in the right branch compared to the high-risk torrent before the disaster. Therefore, we used the moved sediment volume from the right branch and also assumed the sediment runoff from it. The interval of the $1 \mathrm{D}$ simulation was set at $5 \mathrm{~m}$, and the $2 \mathrm{D}$ area simulation mesh was set at $2 \mathrm{~m}$. There were some check dams for forest conservation and ground sills in the Oya-Ohkawa river, and we set the constructions as fixed bed landform from the details of the DEM data.

\section{(2) Simulation conditions}

The moved sediment volume was estimated as approx. $50,000 \mathrm{~m}^{3}$ including void from the difference between DEM before and after the disaster taken with

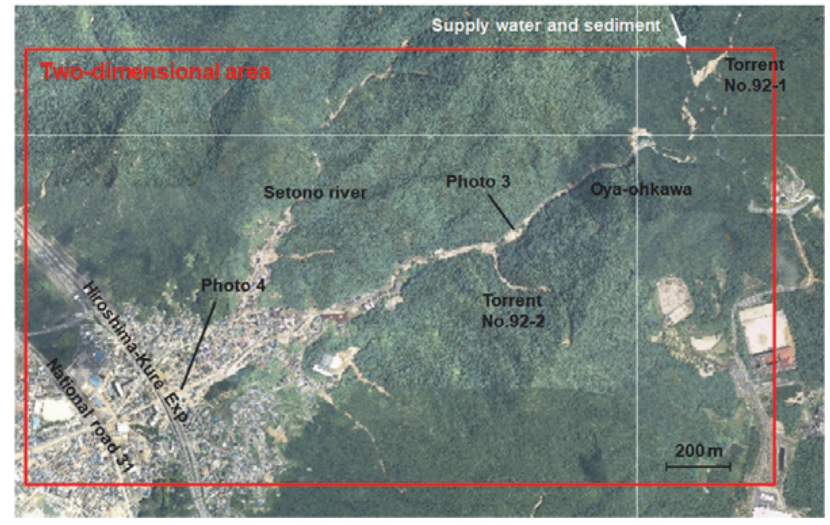

Fig.6 Simulation target in Tennou area.

airborne LiDAR. Therefore, we supplied water and sediment by supplying the mixture discharge and sediment concentration from the upstream. The sediment concentration of the flow was not clear during the event. From the field surveys, it is reported that damaged houses located near Hiroshima Kure Road were buried by sediment deposition, but the window glasses and walls were not broken or destroyed seriously. Therefore, we assumed that the phenomenon was that of bed load continuing over a long period rather than destructive debris flows. In the OyaOhkawa River, some sections were mild slope less than 2 deg., and the equilibrium concentration in the mild area was calculated as 0.0387 ). We set the sediment concentration as 0.03 for the sediment runoff moving to the downstream mild slope area.

We considered the water supply from the rainfall to the target basin $3.1 \mathrm{~km}^{2}$ from the upstream of the 2D area. The target rainfall we applied was $459 \mathrm{~mm}$ accumulation precipitation in the Tennou Rain Observation Station in Kure City. Using the rainfall and considering runoff rate as 0.7 in the mountainous area, the total runoff was calculated. Considering the long period of sediment runoff, we supplied constant discharge with constant sediment concentration in different continuation times. When supplying $50 \mathrm{~m}^{3} / \mathrm{s}$, we supplied 20,000 s (5.6 hrs.); similarly, $25 \mathrm{~m}^{3} / \mathrm{s}$ with $40,000 \mathrm{~s}\left(11.1 \mathrm{hrs}\right.$.) and $10 \mathrm{~m}^{3} / \mathrm{s}$ with $100,000 \mathrm{~s}(27.8 \mathrm{hrs}$.). We also considered the high concentration and short period of debris flow scenario for comparison.

To set the debris flow scenario, the maximum height was $3.1 \mathrm{~m}$ from the trace survey. The height might include the riverbed change, but it was difficult to estimate where the riverbed was during the peak time, so we set it as the flow depth. The river width was $16.8 \mathrm{~m}$. The cross-section was shallow on the right bank and deep on the left bank with a cross-sectional area of approx. $30 \mathrm{~m}^{2}$. Considering the mountainous torrent, we set the Manning's coefficient as $0.04 \mathrm{~m}^{-1 / 3} \mathrm{~s}$, which was a medium value ${ }^{8)}$. Applying hydraulic mean depth as $1.5 \mathrm{~m}$ and slope 0.064 , the 
debris flow peak was calculated as $250 \mathrm{~m}^{3} / \mathrm{s}$. We set the continuous time of the debris flow as $300 \mathrm{~s}$ from the reports of debris flow observed in Japan ${ }^{9}$. From the continuous time and considering four debris flows, we set the sediment concentration as 0.1 for debris flows. We also supplied water flows in the interval and also for the subsequent flow. From trial simulations, sediment moved down to the downstream side when setting $10 \mathrm{~m}^{3} / \mathrm{s}$. Therefore, after supplying the debris flow, we supplied $10 \mathrm{~m}^{3} / \mathrm{s}$ water flow for $300 \mathrm{~s}$ in the interval. We repeated supplying debris flow and water flow four times. Then, we supplied water flow as subsequent flow in $10 \mathrm{~m}^{3} / \mathrm{s}$ with $70,000 \mathrm{~m}^{3}$ (19.4 hrs.), to make the total water supplying condition similar for the other cases. From the field survey of the sediment deposition in the box culvert and also from the recent studies considering the phase shift due to fine sediment containing debris flows ${ }^{10)}$, we set the $0.01 \mathrm{~m}$ as the representative grain diameter and fluid density value with $1,400 \mathrm{~kg} / \mathrm{m}^{3}$. Other parameters were set referring to recent studies of sediment runoff simulations. In this study, we did not consider the height of the buildings. Only the foundations of the buildings were described in the DEM landform data. The influence from the branches was not considered in the simulation. Table 1 shows the simulation cases.

\section{RESULTS AND DISCUSSION}

Figure 7 shows the sediment deposition after the simulation. In all cases, sediment deposition is remarkable at the bight and the slope change point (steep to mild section) with narrow section in the upstream river. Comparing Run1, 2, and 3 with different constant flow rates in low concentration over a long time, Run 1 showed a wide range of sedimentation width in the upstream part (area indicated by the red arrow in Fig.7), which showed valley topography. In Run2 and 3, flow rate is smaller and the width in the upstream part was narrower than in Run1. Generally, the flow rate and the water depth are proportional. When large amounts of sediment deposit in a river, the flood will spread to the roads from the river, and deposition is likely to spread widely. Furthermore, in the area indicated by the red arrow, the sediment deposition in Run4, considering the debris flow scenario, was larger than in Run1-3. Where larger deposition occurred, it was primarily because the sediment concentration was higher than the equilibrium concentration. In Run4 with a combination of debris flow and subsequent water flow, debris flow causes sedimentation first. Since only part of the sediment was eroded in small flow rate, the amount of sediment runoff to downstream side is less than in other cases. On the other hand, in the area shown by the
Table 1 simulation cases.

\begin{tabular}{l|l|l|l|l|l}
\hline Run & $\begin{array}{l}Q_{p} \\
\mathrm{~m}^{3} / \mathrm{s}\end{array}$ & $C$ & $\begin{array}{l}\text { Time } \\
\mathrm{sec}\end{array}$ & $\begin{array}{l}\rho \\
\mathrm{kg} / \mathrm{m}^{3}\end{array}$ & $\begin{array}{l}d \\
\mathrm{~m}\end{array}$ \\
\hline \hline 1 & 50 & 0.03 & 20,000 & 1,400 & 0.01 \\
\hline 2 & 25 & 0.03 & 40,000 & 1,400 & 0.01 \\
\hline 3 & 10 & 0.03 & 100,000 & 1,400 & 0.01 \\
\hline 4 & $\begin{array}{l}250 \\
10\end{array}$ & $\begin{array}{l}0.1 \\
0\end{array}$ & $\begin{array}{l}1,200(300,4 \text { times }) \\
70,000\end{array}$ & 1,400 & 0.01 \\
\hline
\end{tabular}
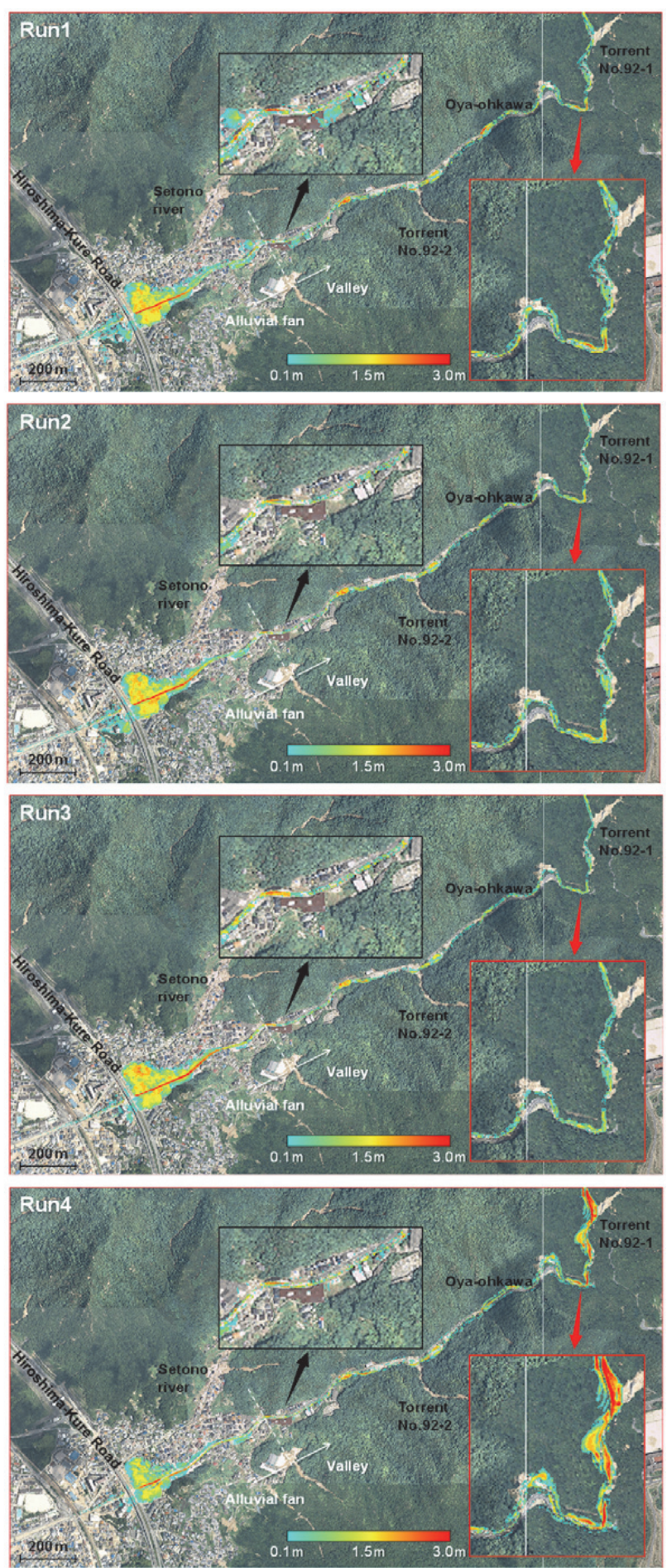

Fig.7 Sediment deposition after the simulation.

black arrow in the downstream, flooding occurred outside the river in Run1 and 4, but not in Run2 and 
3. In the disaster situation, it was reported that the flooding did not occur in this section. Focusing on the Hiro-shima Kure Road in the downstream area, Run4 with $250 \mathrm{~m}^{3} / \mathrm{s}$ large discharge showed smaller sediment deposition area than Runl. Because sediment deposition occurred upstream and the duration of the peak discharge was short, discharge became smaller when the flow moved down to this section. The terrain downstream from this section extended in the transverse direction. In the actual disaster, the boundary between the valley topography and the alluvial fan was the initiation point of the flood.

Upstream from the box culvert, the sediment deposition was remarkable in the channel, and deposition also overflowed to residential area around the river. In large discharge Runl, deposition occurred from the alluvial fan area and spread due to the riverbed rising from deposition. While in Run4 considering debris flow with larger discharge than in Runl, deposition in the upstream affected the sediment runoff to the downstream. The amount of runoff was smaller in Run4, and the deposition range downstream was also smaller than in other cases. Regarding the sediment deposition in the upstream side of the culvert, the deposition length to the channel was long in Run3, followed by Run 2 and ; the shortest was Run 4 . When sediment deposits in the river, flooding tends to occur in the areas surrounding the riverbed rising. Therefore, in Run3 with small discharge, the flooding extended upstream, and eventually the sediment deposition thickness was affected. Figure 8 shows the time series of deposition height in Run3, in which sediment deposition best represented the disaster. As to the sediment and flooding phenomena, Fig.9 shows the time series of the flow depth in Run3.

From $20,000 \mathrm{~s}(5.6 \mathrm{hrs}$.) after the simulation, the sediment moved down to the box culvert around the Hiroshima Kure Road, and the deposition started in the upstream of the culvert. Deposition overflow from the river started from the left bank side, the flooding area expanded to 50,000 s (13.9 hrs.), and the sediment thickness increased thereafter, at a maximum $2.0 \mathrm{~m}$. On the other hand, in the right bank side, the inundation area expanded to $80,000 \mathrm{~s}$ (22.2 hrs.), and then the deposition height gradually increased. The extent of the sediment inundation range was as follows: first, the sediment deposition started in the river, the river section became small and the flood occurred, and water gradually overflowed outside the river (from the flow depth result in $20,000 \mathrm{~s}$ (5.6 hrs.)). Step existed on the right bank side along the Hiroshima Kure Road and sediment was gradually supplied and the deposition expanded. The sediment spread to the right bank side, then spread to the upstream side. On the other hand, when the sediment deposition in the river extended to the upstream side,
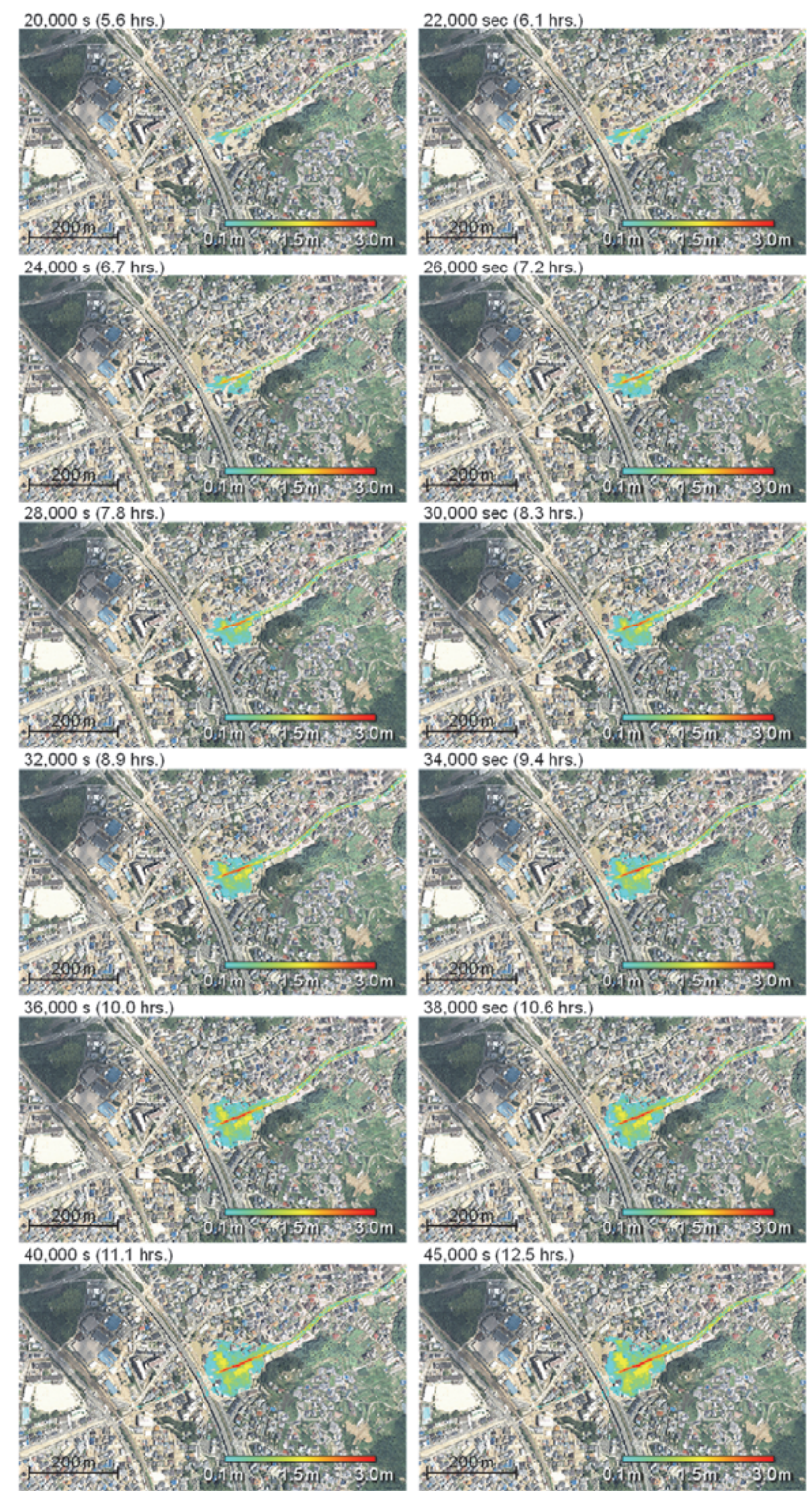

$45,000 \mathrm{~s}$ (12.5 hrs.)
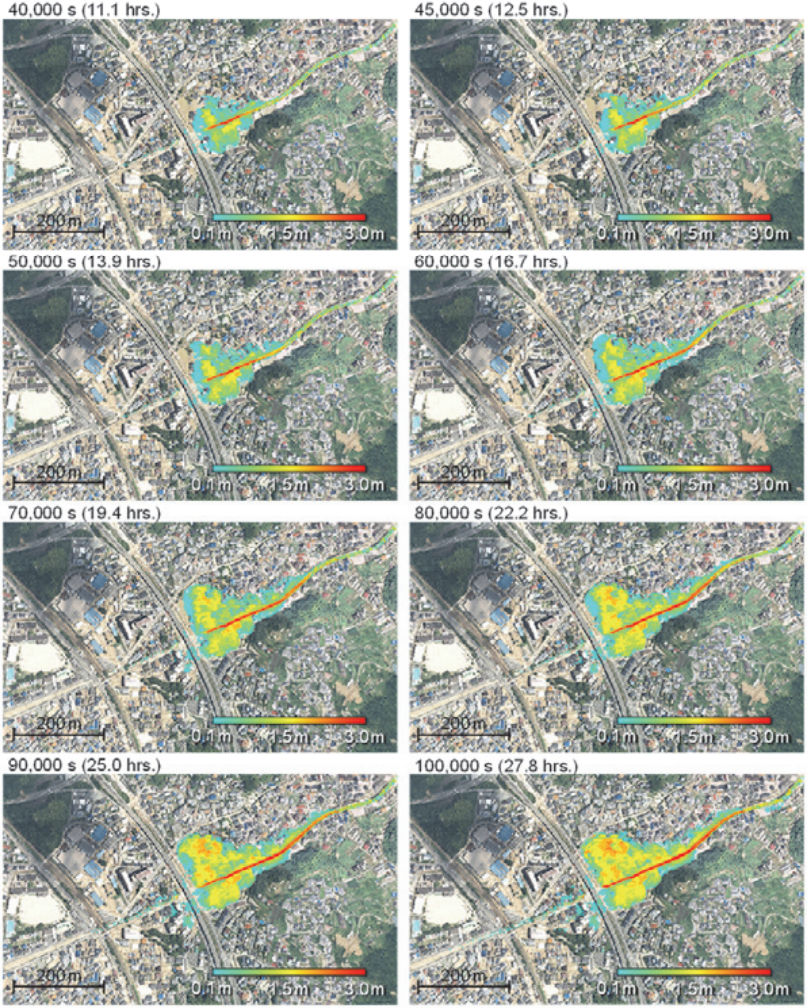

Fig.8 Time series of the deposition in Run3.

water and sediment began to overflow (from the flow depth result in 40,000 s (11.1 hrs.)). Then sediment 

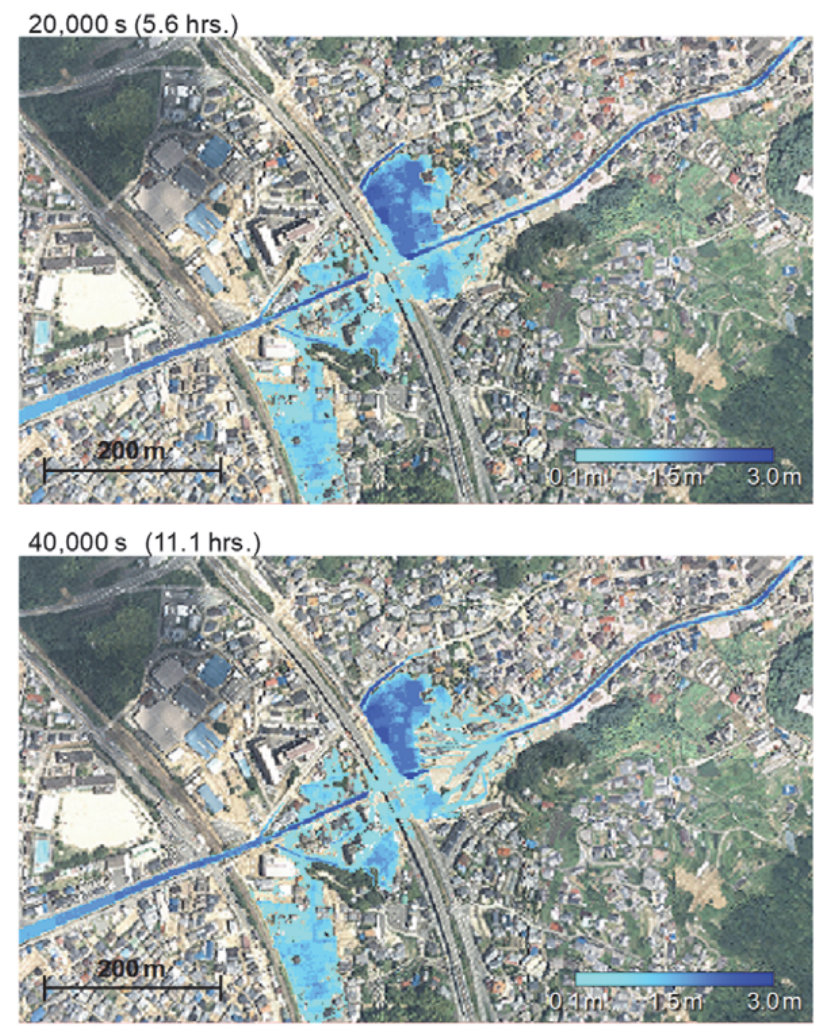

Fig.9 Time series of the flow depth in Run3.

runoff did not move down to the box culvert, and the sediment deposition in the right bank side of the Hiroshima Kure Road became smaller. In the right bank side, overflowed water and sediment from the upstream moved to this section, and deposition height gradually increased.

In Fig.10, the difference in the ground elevation before and after the disaster from the DEM and the simulation results of Run3 deposition are described. The counter range in Fig.10 is different from the results shown in Fig.7 and Fig.8. From Fig.10, deposition area in the upstream of the culvert is larger in the right bank section in the simulation compared to the disaster. And for the area in left bank section is corresponding well to the disaster. In the left bank section, the ground elevation became higher when the distance became far from the river, and deposition was influenced by the landform condition. In the right bank section, from the main river to the branch river had almost the same elevation. Deposition spread to the branch in the simulation result but it did not spread to the branch due to the effect of the buildings during the disaster. Furthermore, in the area shown in the square in Fig.10, deposition occurred outside the river in the simulation but it was not apperaed in the difference in ground elevation as shown in Fig.10. In the ortho photo taken after the disaster and the results shown in Fig.5, some areas showed flood overflow and deposition in the disaster case, but did not show overflow in the difference in ground elevation shown in Fig.10. It seemed to
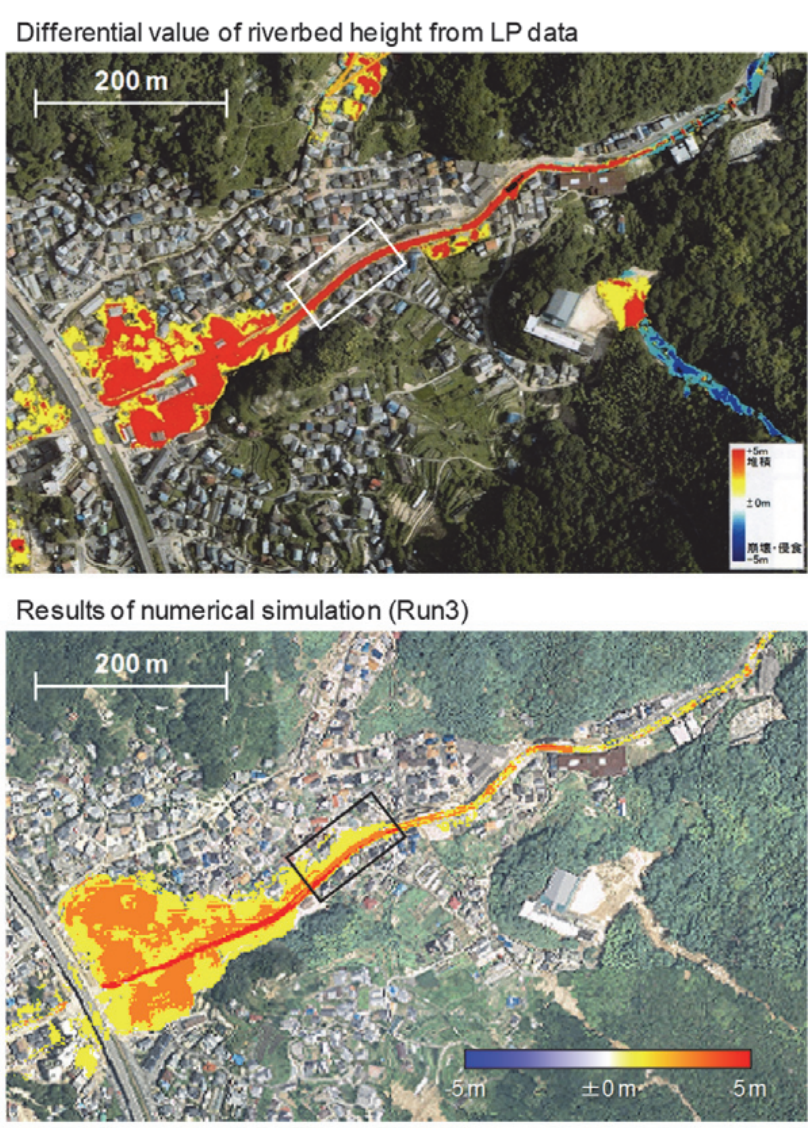

Fig.10 Difference in the ground elevation landform from DEM before and after the disaster ${ }^{2)}$ and the simulation results of deposition in Run3.

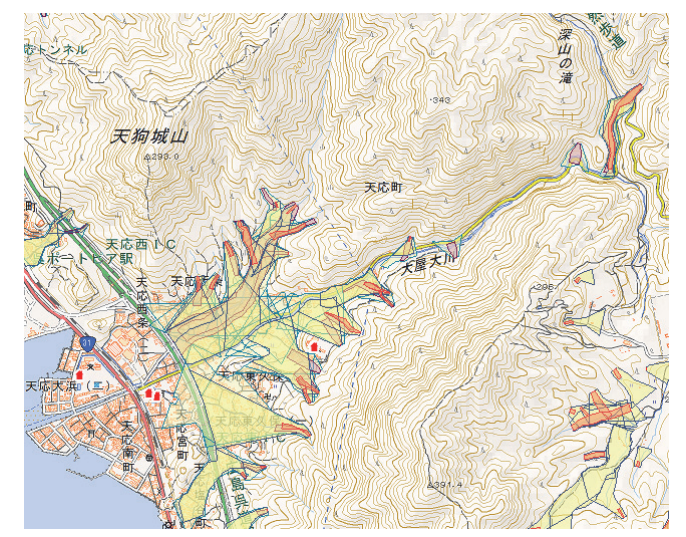

Fig.11 Designated high-risk areas for debris flows in Tennou, Kure City.

happen because the minimum range of the deposition was larger in Fig.10. The average deposition of the four points shown in Fig.5 was approx. $1.5 \mathrm{~m}$ and the points were located outside the river. The average height of the revetment wall of the river was approx. $1.6 \mathrm{~m}$. The simulation results around these areas showed maximum $2.9 \mathrm{~m}$ in the river and maximum $1.5 \mathrm{~m}$ outside the river. Therefore, the simulation results correspond to the disaster situation. From the difference shown in Fig.10, the red color area spread widely, but deposition higher than $5 \mathrm{~m}$ did not appear in the field survey results. 
In Fig.11, the designated high-risk area for debris flows in Tennnou, Kure City is described. Around the Oya-Ohkawa River, the designated area failed to consider the sediment runoff reaching the downstream area moving along the river. The designated area was considered to be prone to direct damage caused by debris flows, such as destruction due to collisions. It also failed to consider the long-time series sediment runoff. However, the image of designated area will lead residents to believe that the downstream area will not be affected by overflow due to deposition in the downstream side. In the Sediment Disaster Prevention Act in Japan, the high risk designated area is set from the landform conditions. When the slope is smaller than two degrees, the area will not be designated. However, in the valley plain area, sediment deposition may occurr on the riverbed and the topography may change during the rainfall event. In the valley plain area, landform can only change in longitudinal profile and can't change in cross sectional profile such as causing flooding and deposition outside from the river. Therefore, only the longitudinal profile changes. As shown in the 2018 disaster in Tennou, sediment runoff continued for a long time and caused large deposition in the area smaller than two degrees. For future work, we will extract similar landform areas that may face sediment and flood damage and also consider effective structural measures to mitigate disaster.

\section{CONCLUSIONS}

The sediment disasters caused by the 2018 heavy rains included not only direct damage from debris flows, such as buildings destruction and significant depositions in alluvial fans, but also sediment and flood damage in the downstream area several kilometers from the mountainous area. In Tennou, Kure City, debris flows occurred and large rocks moved in the upstream area. There were sediment runoffs but no overflows in the midstream area; however, there were overflows in the downstream area. In this study, we conducted field surveys and also applied simulations to study the disaster phenomena and how the overflows occurred in time series. From field surveys, we found that landslides up to 1-2 $\mathrm{m}$ thick and sedi-ment erosion in river caused runoff to the downstream side. Furthermore, woody debris and sediment diameter approx. $1 \mathrm{~m}$ moved in the upstream area, but most of them deposited upstream of the existing dams, and did not move to the downstream side. In the downstream side, there was no sediment deposition in the downstream side of the culvert located in the river. Therefore, culvert blocking seemed to occur. In the simulations, we assumed the scenario culvert blocked, and also considered the sediment runoff in long-time series and in low sediment concentration, such as bed loads. From the simulations, we confirmed that overflow started from the blocked culvert point, but as sediment deposition expanded, the flow section became small in the river and overflow also occurred at the upstream side of the culvert. We maintain that simulation can describe the sediment and flood damage and can consider the detail risk distribution in the affected area. For future work, we will extract similar landform areas that may face sediment and flood damage and also consider effective measures to mitigate disaster.

ACKNOWLEDGMENT: We would like to thank the Ministry of Land, Infrastructure and Transport, Japan, Chugoku Regional Development Bureau, Hiroshima West mountain range Sabo Office, for providing materials such as field surveys.

\section{REFERENCES}

1) Kaibori, M., Hasegawa, Y., Yamashita, Y., Nakatani, K. and other 15 authors : Sediment-related disaster due to heavy rainfall in Hiroshima Prefecture in July, 2018, Journal of the Japan Societyof Erosion Control Engineering, Vol. 71, No. 4, pp. 49-60, 2018 (in Japanese with English abstract).

2) Hiroshima Prefecture: Matters to be considered in sediment disasters designated high-risk area, Study group on future countermeasures for floods and sediment disasters considering July heavy rain in 2018, First meeting of Sabo Division, Document 4-1, Retrieved March 22, 2019, from https://www.pref.hiroshima.lg.jp/uploaded/attachment/330 358.pdf, 2018 (in Japanese).

3) Hiroshima Prefecture: Matters to be considered in sediment disasters designated high-risk area, Study group on future countermeasures for floods and sediment disasters considering July heavy rain in 2018, Second meeting of Sabo Division, Document 4, Retrieved March 22, 2019, from https://www.pref.hiroshima.lg.jp/uploaded/attachment/332 034.pdf, 2018 (in Japanese).

4) Hiroshima Prefecture: Matters to be considered in sediment disasters designated high-risk area, Study group on future countermeasures for floods and sediment disasters considering July heavy rain in 2018, Second meeting of Sabo Division, Document 2, Retrieved March 22, 2019, from https://www.pref.hiroshima.lg.jp/uploaded/attachment/330 356.pdf, 2018 (in Japanese).

5) Horiuchi, S., Iwanami, E., Nakatani, K., Satofuka, Y. and Mizuyama, T.: Development of "Hyper KANAKO", A debris flow simulation system using laser profiler data, Journal of the Japan Society of Erosion Control Engineering, Vol. 64, No. 6, pp. 25-31, 2012 (in Japanese with English abstract).

6) Nakatani, K., Kosugi, M., Satofuka, Y. and Mizuyama, T.: Influence of housing and roads on debris flow flooding and deposition in alluvial fan areas : Case study on debris flows in Hiroshima, Japan, in August 2014, Journal of the Japan Society of Erosion Control Engineering, Vol. 69, No. 5, pp. 3-10, 2017 (in Japanese with English abstract).

7) Takahashi, T. and Nakagawa H. : Prediction of stony debris flow induced by severe rainfall, Journal of the Japan Society of Erosion Control Engineering, Vol. 44, No. 3, pp. 47-52, 1991 (in Japanese with English abstract). 
8) Japan Society of Civil Engineers (JSCE): Hydraulics Formulae, pp. 89, Maruzen, 1999(in Japanese).

9) Ikeda, A., Monma, N., Horiuchi, S. and Yamada, T.: Debris flows generated at Kitayama Valley of the Name River, Journal of the Japan Society of Erosion Control Engineering, Vol. 51, No. 2, pp. 31-38, 1998 (in Japanese with English abstract).

10) Nakatani, K., Furuya, T., Hasegawa, Y., Kosugi, K. and
Satofuka, Y.: Study on fine sediment phase change factors and influence on debris flow behavior, Journal of the Japan Society of Erosion Control Engineering, Vol. 70, No. 6, pp. 3-11, 2018 (in Japanese with English abstract).

(Received August 31, 2020)

(Accepted September 17, 2020) 